\title{
Vesico-vaginal fistula post cold cup bladder biopsy: mini review
}

\author{
This article was published in the following Dove Press journal: \\ Open Access Journal of Urology \\ 13 September 2010 \\ Number of times this article has been viewed
}

\author{
Abigail Mawhinney,** \\ Ammar Hameed ${ }^{2, *}$ \\ Ali Thwaini' \\ Colin Mulholland' \\ 'Belfast City Hospital, Urology \\ Department, Belfast, Northern \\ Ireland, UK; ${ }^{2}$ Addenbrookes University \\ Hospital, Urology Department, \\ Cambridge, UK \\ *These authors contributed equally to \\ this paper
}

Introduction: We report a case of a vesico-vaginal fistula (VVF) post cold cup biopsy; to our knowledge this is the only reported case. We present the clinical history/presentation, investigation and the outcome of the treatment. VVFs are among the most distressing complications of gynecologic and obstetric procedures. The risk of developing a VVF is more than $1 \%$ after radical surgery and radiotherapy for malignancies. Management of these fistulas has been better defined and standardized over the last decade.

Methods and results: A case of low grade superficial bladder cancer was treated with multiple resections of bladder tumor and a single installation of mitomycin post initial resection which successfully cleared her bladder cancer, but nevertheless led to a small size and scarred bladder. In addition there was a long history of smoking with its effects on tissue integrity and healing. VVFs are very rare and are an unpleasant outcome post a cold cup biopsy, adding to the psychological and social effects of the surgical treatment.

Conclusion: Although cold cup biopsy is a normal day procedure performed by both residents and consultants, consensus should exist on how to treat a patient who has a bladder with defective integrity and small capacity. The rate of successful fistula repair reported in the literature varies between $70 \%$ and $100 \%$ in nonradiated patients, with similar results when a vaginal or abdominal approach is performed, the mean success rates being $91 \%$ and $97 \%$, respectively.

Keywords: vesico-vaginal fistula, vaginal fistula, surgical repair of vaginal fistula, management of vaginal fistula

\section{Introduction}

Vesico-vaginal fistula (VVF) is an abnormal communication between the bladder and the vagina that allows continuous involuntary urine leakage into the vaginal vault. We report a 56-year-old female presenting with a VVF following a straightforward cold cup bladder biopsy as a day procedure, with the work up, diagnosis, and management. In addition, a literature review with consensus of management is presented.

\section{Case report}

A 56-year-old female with low grade, superficial transitional cell carcinoma of the bladder (TCC G2 pTa) for the last 4 years, came electively for her annual check cystoscopy. She had had a vaginal hysterectomy 10 years previously for postmenopausal bleeding. She is a chronic heavy smoker.

At the time of flexible cystoscopy a red patch was noted at the trigone of the bladder, close to the site of the previous transurethral bladder tumor resection site. General anesthetic cystoscopy and 2 cold cup bladder biopsies were arranged and performed
Correspondence: Ammar Hameed Urology Specialist Registrar, Department of Urology, Addenbrookes University Hospital, Cambridge, CB2 0QQ, UK Email dr_ahameed@hotmail.com 
by an experienced trainee. It was a straightforward cold cup biopsy. The biopsies were not deep but the patient had a relatively thin bladder owing to previous resections. No perivesical fat was seen at the end of the procedure which was followed by Bugbee cystodiathermy. The patient was discharged home on the same day without a catheter and after successful voiding.

The biopsy histopathology results showed mild inflammation only. Three weeks later the patient reported sudden onset continuous leakage of urine. Urine dipstick analysis was normal, and clinical examination failed to show anything of significance apart from continuous vaginal wetting with urine. Cystoscopy was arranged - we did not use methylene blue as the fistula was easily diagnosed clinically, cystoscopically, and radiologically by IVU (intravenous urogram). Cystoscopy showed a well-formed fistulous tract at the site of the recent bladder biopsy, close to the right ureteric orifice (Figure 1). Radiological investigation was carried out as shown below and the fistulous tract was classified as a complex fistula. An IVU revealed normal upper tracts with contrast in the vagina (Figure 2).

\section{Surgical repair}

The rate of successful fistula repair reported in the literature varies between $70 \%$ and $100 \%$ in nonradiated patients, with similar results when a vaginal or abdominal approach is performed, the mean success rates being $91 \%$ and $97 \%$, respectively. Many institutions prefer to perform a urinary diversion. ${ }^{1}$

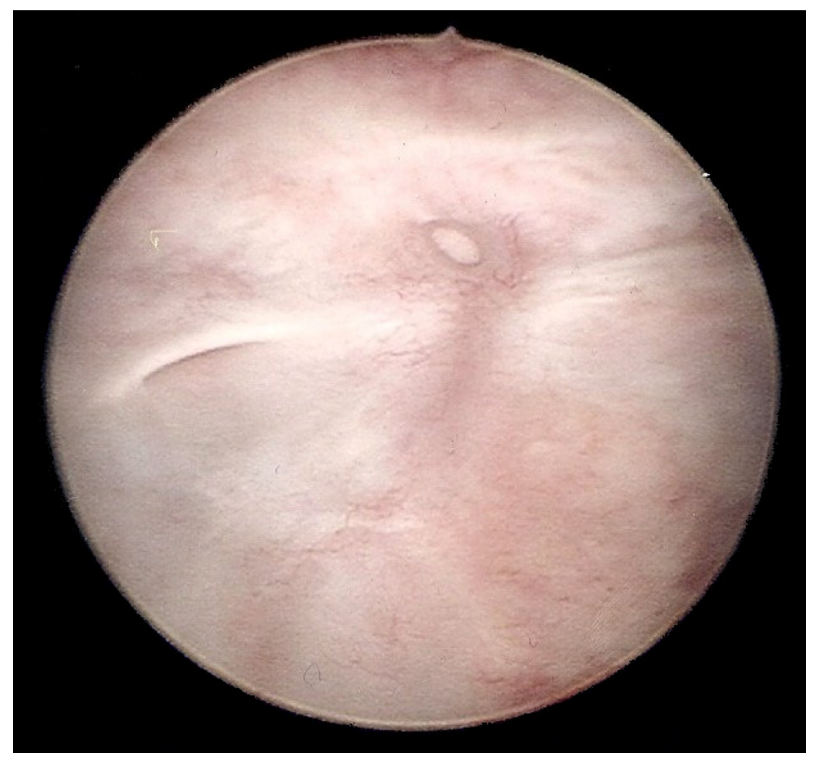

Figure I Cystoscopy image showing scarring around the right ureteric orifice and discrete fistula to centre of trigone.

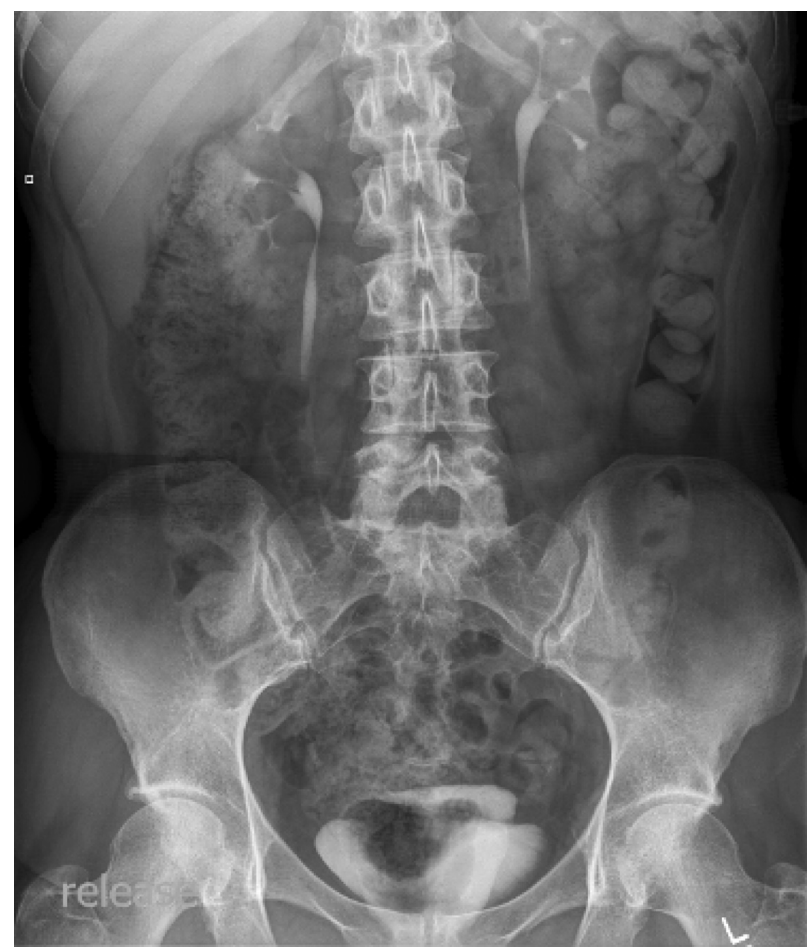

Figure 2 IVU showing normal upper tract with contrast in the urinary bladder and vagina simultaneously.

A classical transabdominal repair of the VVF was performed. The bladder was bivalved in the midline position, down to the level of the VVF. Both ureteric orifices were identified at the time of the procedure and were catheterized intraoperatively through the cystotomy incision (Figure 3).

The fistula was as described, in the trigone, at the interureteric bar, sparing the ureteric orifices. The fistula was dissected out between the bladder and vagina, taking care not to excise it so as not to compromise the tissues and increase the size of tissue to be repaired. After separation of the bladder from the vagina, both openings in the bladder and vagina were closed separately using interrupted tension-free, nonopposing sutures using $3 / 0$ vicryl. This together with creating an omental flap interposing between the bladder and the vagina and fixed in position using interrupted 2/vicryl sutures.

The ureteric catheters were removed after repair of the VVF. A suprapubic catheter and a urethral catheter were positioned and a pelvic drain was placed at the end of the procedure. Antibiotics were prescribed for 3 days postoperative for prophylaxis with broad spectrum antimicrobial. The patient had an uneventful recovery: epidural analgesia was discontinued on day 2 postoperatively with oral analgesia in place. The catheter was removed three weeks postoperatively. The patient was fully continent at subsequent review. 


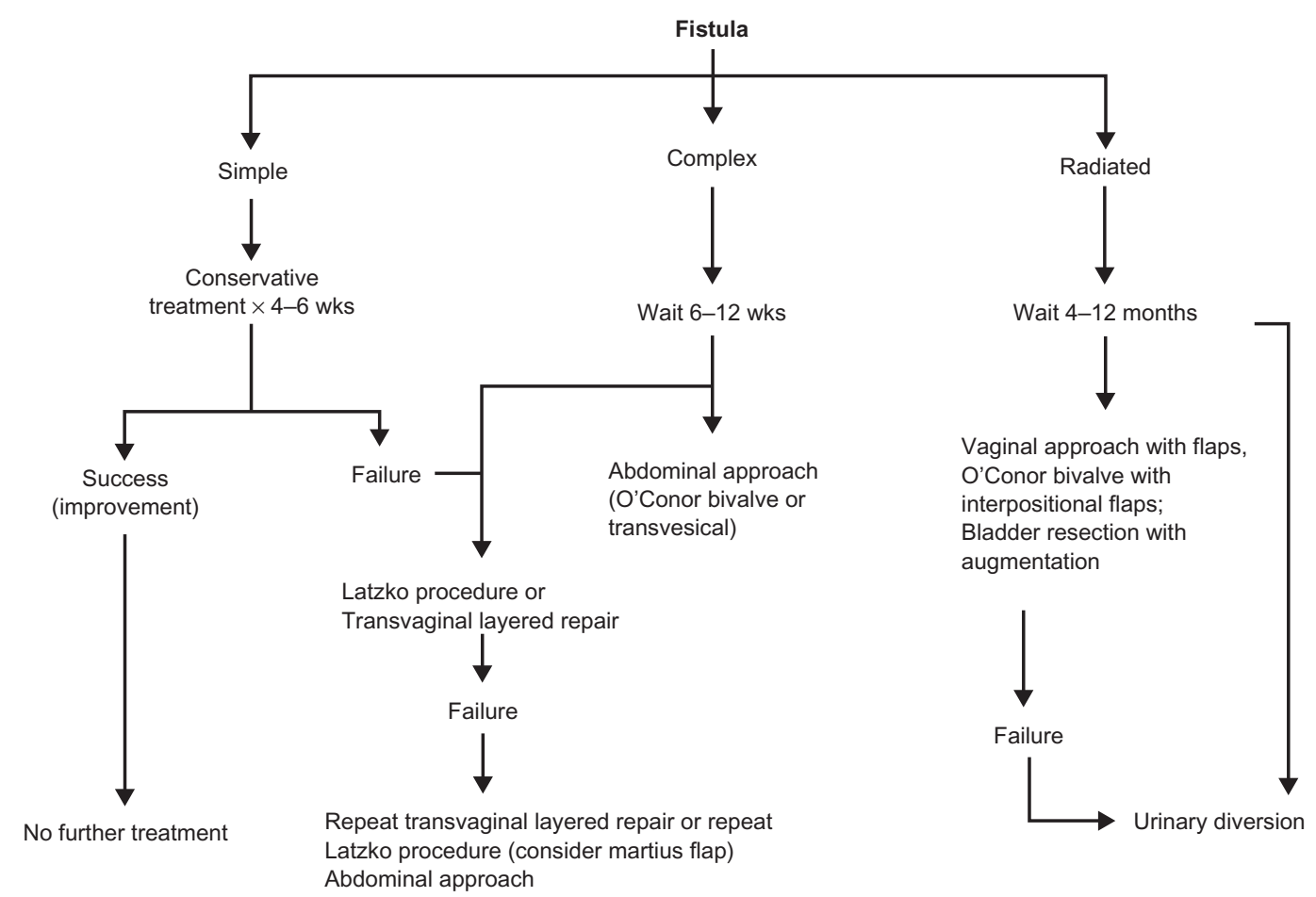

Figure 3 Algorithm of vesico-vaginal fistula repair.

\section{Discussion}

A VVF can be a result of 'obstetric trauma, surgery, infections, congenital anomalies, malignancy and malignancy treatment'. ${ }^{2}$ In the United States, the majority of VVFs arise as complications of gynecologic surgery, with the preceding procedure most frequently being a total abdominal hysterectomy. ${ }^{3}$ In the series by Lee et al, $90 \%$ of the VVFs encountered were the result of surgical treatment for a 'benign' condition, with total abdominal hysterectomy accounting for $70 \%$ of the fistulas. ${ }^{4}$ An operation for treatment of cancer carries a higher risk of urologic complications. There is approximately a $1 \%$ risk for ureteral and vesical injuries associated with radical hysterectomy as treatment for cervical cancer. ${ }^{5}$ Postoperative fistulas are usually an early complication, appearing approximately 10 days after hysterectomy, while radiation-induced fistulas frequently occur many years after treatment. ${ }^{6}$ Even though numerous predisposing factors in the development of the postoperative fistula have been identified (ie, infection, ischemia, arteriosclerosis, pelvic inflammatory disease, previous uterine surgery, uterine myomata, cancer treatments, and diabetes), the vast majority occur under 'very normal operative circumstances'?

The etiology of VVF is different in various parts of the world. In developing countries, they are the result of obstetric complications, possibly due to inadequate medical care, and/or early age at conception with the resultant increase in cephalo-pelvic disproportion and malpresentation at time of delivery causing a prolonged obstructed labor. This would result in necrosis secondary to pressure of the foetal head on the vagina. However the incidence has decreased over the past 2 decades. ${ }^{8}$ Fistulas can be classified according to size, as shown in Table 1.

The situation is entirely different in developed countries, with gynecologic procedures being the most common iatrogenic factor. In the Mayo Clinic, $85 \%$ of the VVFs were related to pelvic operations and $75 \%$ were related to hysterectomy, with more than $60 \%-70 \%$ being secondary to simple, uncomplicated, total abdominal or vaginal hysterectomy. Only $5 \%$ of these VVFs were obstetric and $10 \%$ occurred after radiotherapy. Obstetric causes of fistulas in modern centers include vaginal lacerations from forceps rotations, cesarean delivery, hysterectomy, and ruptured uterus. ${ }^{9}$

Table I Fistula classification'

Type

Simple: (small, nonradiated, single)

Complex: (medium, large, radiated, multiple, recurrent)

Size

Small: $\leq 0.5 \mathrm{~cm}$

Medium: $0.6-2.4 \mathrm{~cm}$

Large: $\geq 2.5 \mathrm{~cm}$ 
Less frequent causes of VVF include various urological and gastrointestinal surgeries. Such surgeries include suburethral sling procedures, urethral and bladder neck surgery, and surgery for pelvic carcinomas. ${ }^{10}$ There have been no documented cases in the literature of VVF secondary to cystodiathermy. ${ }^{11}$

Factors that preclude success of treatment include small bladder size, urethral destruction, circumferential involvement, and severe vaginal scarring. ${ }^{12,13}$

In our case the three important risk factors were identified: prior hysterectomy and bladder endoscopic resections resulting in a scarred, small capacity bladder, in addition to a long history of smoking with its ill effects on tissue integrity and healing. Despite the fact that the patient admitted to having stopped smoking for a short while, her chronic smoking habit had certainly affected her bladder tissue integrity.

Once a fistula is diagnosed, the most important therapeutic decisions are on the type of procedures and the timing as to when to perform the treatment. Initial repair is critical since data reveal that the first attempt at repair is usually the most successful. One of the main controversies is when to surgically correct a postoperative VVF. The classical teaching is to wait 2-4 months using continuous drainage of the bladder. This allows resolution of the postoperative inflammation and edema. This conservative approach usually results in a spontaneous fistula healing rate of at most only $15 \%-20 \%$ of cases, when the fistula is simple and small. ${ }^{14}$ Nevertheless, considering that recurrent fistulas are always more difficult to repair, conservative treatment should be attempted. We use conservative management for simple fistulas $(\leq 5 \mathrm{~mm}$, nonradiated and single). If healing does not occur, and there is no significant improvement within 2 months, we will then resort to surgical management. Some authors report a success rate of up to $100 \%$ when fistulas were repaired in as short a time as 6 weeks from diagnosis. ${ }^{15,16}$

The best time to repair a fistula is when the edema and inflammation subside and there is no infection. The other important factor is adherence to surgical technique, with various techniques being adopted by various urologists depending on fistula characteristics.

The main steps used in our center to achieve successful repair include: mobilization of tissues, proper identification and excision of the damaged parts, and layer closure without tension.

Complex fistulas are usually the most troublesome. There are instances when the vaginal approach can be employed as management of a complex fistula. This situation usually mandates the use of ancillary vascular supplies to the area in the form of either Martius bulbocavernosus flaps or gracilis myocutaneous flaps. The abdominal approach can be performed using a transvesical (fistula excision) or an extravesical (bivalve technique) approach. In reality both procedures involve the opening of the bladder.

The mean success rate of VVF repair described in the literature, independent of the access route and tissue conditions, approaches $90 \%$ and varies between $40 \%$ and $100 \%$. The vaginal route registers a success rate between $40 \%$ and $100 \%$, the abdominal route between $70 \%$ and $100 \%$ when radiated fistulas are included. When the fistula is complex (including radiated fistulas) the Martius flap is often used in association with the vaginal repair. The abdominal route is more frequently preferred for selected cases (complex fistulas). Our preferred method is the bivalve technique. When the fistula occurs in a radiated field, various types of flaps (peritoneal, omental, myofascial, intestinal) are potentially useful. ${ }^{17}$

\section{Conclusion}

VVF is a devastating condition that could result from even minor surgical procedures on the urinary bladder; hence the utmost vigilance is paramount in obtaining biopsies and performing cystodiathermy at the trigone and base of bladder.

\section{Disclosure}

The authors report no conflicts of interest in this work.

\section{References}

1. Angioli R, Penalver M, Muzii L, et al. Guidelines of how to manage vesicovaginal fistula. Crit Rev Oncol Hematol. 2003;48(3):295-304.

2. Menchaca A, Akhyat M, Gleicher N, Gottlieb L, Berstein J. The rectus abdominis muscle flap in a combined abdominovaginal repair of difficult vesicovaginal fistulae. A report of three cases. J Reprod Med. 1990; 35(5):565-568.

3. Tancer M. Observations on prevention and management of vesicovaginal fistula after total hysterectomy. Surg Gynecol Obstet. 1992; 175(6):501-506.

4. Lee RA, Symmonds RE, Williams TJ. Current status of genitourinary fistula. Obstet Gynecol. 1988; 72(3 Pt 1):313-319.

5. Penalver M, Angioli R. Urinary diversion. Chapter 11. In: Hurt WG, editor. Urogynecologic surgery. 2nd ed. Philadelphia, PA: LippincotRaven Press, 2000:193-206.

6. Carr LK, Webster GD. Abdominal repair of vesicovaginal fistula. Urology. 1996;48(1):10-11.

7. Margolis T, Mercer LJ. Vesicovaginal fistula. Obstet Gynecol Surv. 1994;49(12):840-847.

8. Obi SN, Ozumba BC, Onyebuchi AK. Decreasing incidence and changing aetiological factors of vesico-vaginal fistula in south-east Nigeria. J Obstet Gynaecol. 2008;28(6):629-631.

9. Lee RA, Symmonds RE, Williams TJ. Current status of genitourinary fistula. Obstet Gynecol. 1988;72(3 Pt 1):313-319. 
10. Starkman JS, Meints L, Scarpero HM, Dmochowski RR. Vesicovaginal fistula following a transobturator midurethral sling procedure. Int Urogynecol J Pelvic Floor Dysfunct. 2007;18(1):113-115.

11. Moir JC. Vesicovaginal fistulae caused by wedge-resection of the bladder neck. Br J Surg. 1966;53(2):102-104.

12. Tancer ML. Observations on prevention and management of vesicovaginal fistula after total hysterectomy. Surg Gynecol Obstet. 1992;175(6):501-506.

13. Nardos R, Browning A, Chen CC. Risk factors that predict failure after vaginal repair of obstetric vesicovaginal fistulae. Am J Obstet Gynecol. 2009;200(5):578.e1-578.e4.

14. Thompson JD. Operative injuries to the ureter: prevention, recognition and management. In: Thompson JD, Rock JA, editors. TeLinde's operative gynecology. Seventh ed. Philadelphia, Pa, JB Lippincott, 1992:759-783.
15. Blandy JP, Badenoch DF, Fowler CG, Jenkins BJ, Thomas NWM. Early repair of iatrogenic injury to the ureter or bladder after gynaecologic surgery. J Urol. 1991;146:761-765.

16. Moriel EZ, Meirow D, Zilberman M, Farkas A. Experience with the immediate treatment of iatrogenic bladder injuries and the repair of complex vesico-vaginal fistulae by the transvesical approach. Arch Gynecol Obstet. 1993;253:127-130.

17. Kapoor R, Ansari MS, Singh P, et al. Management of vesicovaginal fistula: An experience of 52 cases with a rationalized algorithm for choosing the transvaginal or transabdominal approach. Indian J Urol. 2007;23(4):372-376.

\section{Publish your work in this journal}

The Open Access Journal of Urology is an international, peer-reviewed, open access journal publishing original research, reports, editorials, reviews and commentaries on all aspects of adult and pediatric urology in the clinic and laboratory including the following topics: Pathology, pathophysiology of urological disease; Investigation and treatment of

\section{Dovepress}

urological disease; Pharmacology of drugs used for the treatment of urological disease. The manuscript management system is completely online and includes a very quick and fair peer-review system, which is all easy to use. Visit http://www.dovepress.com/testimonials.php to read real quotes from published authors.

Submit your manuscript here: http://www.dovepress.com/open-access-journal-of-urology-journal 